\title{
Social Network Site Usage by Small- and Medium-Sized Businesses: Understanding the Motivations and Barriers
}

\author{
Yazn Alshamaila ${ }^{1}$ \\ ${ }^{1}$ King Abdullah II School for Information Technology, The University of Jordan, Amman, Jordan \\ Correspondence: Yazan Alshamaileh, The University of Jordan, Business Information Technology Department, P. \\ O. Box 11942, Amman, Jordan. Tel: 962-6535-5000. E-mail: y.shamaileh@ju.edu.jo
}

Received: January 8, 2018

Accepted: January 23, 2018

Online Published: February 27, 2018

doi:10.5539/mas.v12n3p41

URL: https://doi.org/10.5539/mas.v12n3p41

\begin{abstract}
This paper contributes to a growing body of research on the process by which small- and medium-sized businesses (SMBs) adopt social network sites (SNSs) as part of their business strategies. If SMBs make use of SNSs, they could potentially compete with big corporations, flattening the marketplace. Open-ended online survey questions were used to collect data from 24 different social media experts in the Hashemite Kingdom of Jordan. Jordan was selected for this study because $90 \%$ of its adult Internet users are active on SNSs, a percentage that surpasses many emerging and developed countries. This research project identifies (a) relative advantage, (b) community demand, and (c) interactivity as motivating factors for SNS adoption. The survey results also reveal that (a) top management belief, (b) firm readiness, (c) negative comments and reviews, and (d) a low level of awareness are barriers to SNS adoption by SMBs in Jordan. The present study should prove to be particularly valuable to academics and business managers to formulate their business strategies regarding SNS adoption, and to pave the way for more research to assess likely changes.
\end{abstract}

Keywords: barriers, Information technologies adoption, Motives, small to medium-sized enterprises, Social Network Sites

\section{Background}

Social network sites (SNSs) help firms target more engaged customers, despite excluding a few due to their inability to stay engaged (Culnan, McHugh, \& Zubillaga, 2010). Furthermore, firms use SNSs as a platform to help them construct human relationships through online communication, enabling them to conduct data analyses of these interactions, ascertain their performance, and improve areas of concern (Gandomi \& Haider, 2015). In the context of small- and medium-sized businesses (SMBs) in particular, SNSs help small businesses stand out from the competition, including big firms that have established marketing channels. For small businesses, SNSs are among the best approaches to gain marketing collateral at an affordable cost; by using SNSs, they can stay engaged with their customers and build their businesses with no need to spend money on expensive graphics to market themselves (Nobre \& Silva, 2014). Because of SNSs interactivity, firms are beginning to consider them more effective tools than traditional media and websites in building relations with the public (e.g., Kelleher \& Miller, 2006; Kent, 2008; Sweetser \& Metzgar, 2007). Businesses are able to reach out to the larger market segments that use such social sites. For instance, through Facebook, clients are able to air their views regarding company services, giving firms the opportunity to respond to their concerns and rectify those hitches. However, unplanned usage of SNSs could harm firms' reputation through unattended negative comments and feedback about businesses products and services (MessageLabs, 2007). In fact, despite the common benefits that SNSs offer to SMBs, a literature review highlights a list of barriers that hinder adoption, such as privacy and security issues, regulation concerns, and top management belief. The key motivations and barriers will be reviewed in detail below.

\subsection{Framing Organizational SNS Adoption}

Different studies discussed SNS usage among SMBs in the context of marketing, entrepreneurship (e.g., Tiago \& Veríssimo, 2014), and performance outcomes (e.g., Ainin, Parveen, Moghavvemi, Jaafar, \& Shuib, 2015). The research community has generally passed over the distributed nature of SNSs. It has given little attention to the identification of motivating factors and barriers that could affect the SNS adoption process. In addition to this, previous studies mainly highlighted SNS implementation success and the adoption of related critical success factors (e.g., de Araújo \& Zilber, 2016; Ainin, Parveen, Moghavvemi, Jaafar, \& Shuib, 2015, Zeiller \& Schauer, 
2011). Those studies emphasized post-adoption factors. Inherent in the research are businesses that have already utilized SNS technology (Garverick, 2014). As a result, potential barriers that prevent selection have not been studied in depth. To fill these gaps, the current study is an attempt to explore these key adoption factors and pave the way for more research to assess likely changes. This study will use the Diffusion of Innovation (DOI) theory developed by Rogers (2003) to explain the main technological factors involved in the spread of this technology. The network externalities theory will serve as a basis to explain the main environmental factors. Finally, literature on adoption will be used to analyze organizational factors and adoption barriers.

The term network externalities refers to the value added to a product of service as a result of an increased number of customers (Shapiro, Varian \& Becker, 1999). Farrell \& Klemperer (2007) found that when a specific product or service is adopted by different users, this popularity encourages potential consumers to do the same, thus increasing the adoption numbers. The network effect was first applied to empirical telecommunication studies (e.g., Squire, 1973; Rohlfs, 1974; Kahn \& Shew, 1987; Einhorn, 1993; Panzar \& Wildman, 1995; Barnett \& Kaserman, 1998; Crémer, 2000; Yannelis, 2001; Mason \& Valletti, 2001; Gandal, Salant, \& Waverman, 2003; Shy, 2001). The same concept could be applied to SNSs among SMBs. With the increase of users' interaction on SNSs, a community demand developed for methods of communication among current and potential consumers and with SMBs. This encouraged SNS adoption among SMBs.

This study aims to integrate both the DOI and network externalities theories as well as current literature into one coherent framework. According to this framework, key adoption factors will be simply_divided into two inclusive sets: motives and barriers. We believe these two groups encompass the determinants needed to understand SNS adoption in the context of Jordanian SMBs (see Figure 1). The following sections will provide an overview of the main constructs in the framework.

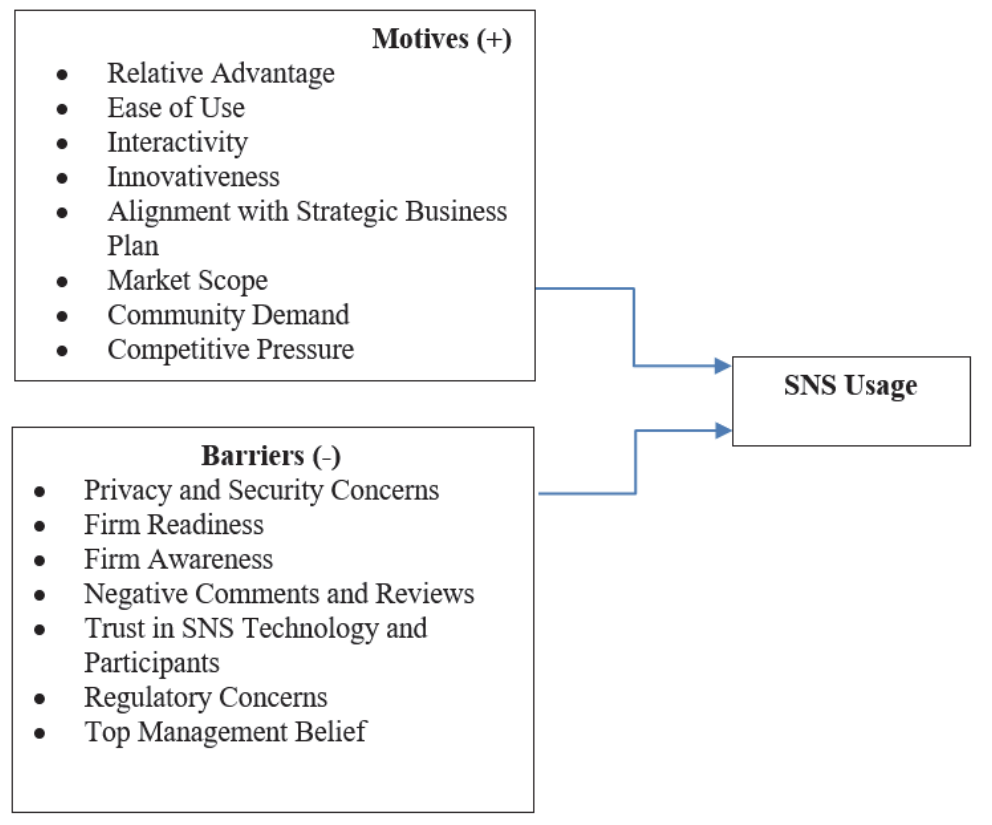

Figure 1. Framework for SMB Adoption of SNS Services

\subsection{Motivation for SMBs to Adopt SNS Usage}

Relative Advantage: Rogers (2003) defined relative advantage as the level of acceptance of new innovations due to their being perceived as exceeding the suppressed idea. Rogers (2003) indicated that acceptance would be more likely if the innovation was considered to have relative advantage. Many previous studies showed that relative advantage is the main factor for SMBs in adopting new information and communication technology (ICT) innovations (e.g., see Shah Alam, Ali \& Jani, 2011; Elmazi, Vukaj, Gega, \& Elmazi, 2011). According to Wanyoike, Mukulu, and Waititu (2012), SNSs make the work easy, reduce costs, satisfy the customers, and improve productivity. From an ICT innovation perspective, the relative advantages of SNSs are noticeable.

Ease of Use: The likelihood of adoption will decrease if the innovation is complex to use (Rogers, 2003). Davis (1989) defined ease of use as the level of ease experienced in using a system. Many studies showed that ease of 
use is positively related with technology adoption among SMBs. Mirchandani \& Motwani (2001), Daniel \& Grimshaw (2002), and Grandon and Pearson (2004), among others, suggested that applications that are easier to use are more likely to be adopted than complex ones. In fact, popular social networking sites are designed to be user-friendly.

Interactivity: Liu and Shrum (2002) defined interactivity as "the degree to which two or more communication parties can act on each other, on the communication medium, and on the messages and the degree to which such influences are synchronized" (p. 54). Since social media became popular, studies have taken an interest in examining the strategies behind online constituencies' relationships (Smith, 2010). Researchers such as Kelleher and Miller (2006), Kent (2008), and Sweetser and Metzgar (2007) pointed out that due to the interactivity features that SNSs provide, SNSs and blogs were more effective than traditional media and websites in building relations with the public. Saffer, Sommerfeldt \& Taylor (2013) explained that Facebook and Twitter were more effective in relationship-building communication than websites lacking interactivity features. The presence of organizations and businesses on SNSs alone is not enough (Cone, 2008); the interaction between the organization and its consumers makes the difference. Jo and Kim (2003) showed that relationships can be cultivated through interactivity and involvement. Interactivity provides better feedback for firms, encouraging responsiveness and a flow of information between the parties (Sundar, Kalyanaraman, \& Brown, 2003; Kietzmann, Silvestre, McCarthy, \& Pitt, 2012). Social media usage is influenced positively by interactivity (Odoom, Anning-Dorson, \& Acheampong, 2017), which in its turn influences SMBs' adoption of SNSs.

Innovativeness: Innovativeness occurs when an organization's receptivity toward new ideas is a key factor in the adoption decision (e.g., see Lin \& Jeffres, 1998; Marcati, Guido, \& Peluso, 2008). Many studies (Rogers \& Shoemaker, 1971; Leung \& Wei, 1998; Lin \& Jeffres, 1998) investigated how this factor plays a major role in ICT innovation adoption. Marcati et al. (2008) argued that receptiveness toward new ideas was a key factor in SMBs' innovation adoption on a firm level. A number of authors have considered the positive effects of this factor (e.g., Hirschman, 1980; Alshamaila, Papagiannidis, \& Li, 2013; and Rogers, 2003). It plays an effective role in decisionmaking, especially in SMBs (Marcati et al., 2008).

\begin{abstract}
Alignment of SNS Use with Business Strategy: Firm managers want adopted innovations to be compatible with their companies' values and strategic technological needs (Rogers, 2003). Henderson and Sifonis (1988) defined this factor as the effective linkage between the strategic ICT plan and the strategic business plan. Several studies have highlighted the importance of SNS alignment with the strategic business plan. Burn and Szeto (2000) argued that a firm's success not only relies on the ICT strategy but the business strategy, as well, and close alignment between the two. Broadbent and Weill (1993) stated that a more effective process of alignment between the two can be achieved by increasing the dialogue between business and ICT managers. Other researchers, such as Bharadwaj (2000) and Armstrong and Sambamurthy (1999), studied the importance of ICT strategy alignment with the strategic business plan.
\end{abstract}

Market Scope: Zhu, Kraemer, \& Xu (2003) defined market scope as the horizontal extent of a company's operations. Several studies have established that market scope can play a key role in technology adoption. For example, Lee and Whang (2004) examined globalization's influence on SMBs' intention to adopt e-business. Hsu, Kraemer, \& Dunkle (2006) argued that the more global a firm is, the greater its diversity and volume of e-business use will be. $\mathrm{Xu}$, Rohatgi, and Duan (2007) found a positive relation between globalization and Internet adoption. This argument presented a firm's market scope as a potential factor for SNS adoption among businesses.

Community Demand: Carmichael, Turgoose, Gray, Todd, \& Nadin, (2000) defined community demand as customers' feedback and demand, both of which are key factors in SMBs' innovation adoption. Poon and Swatman (1999) and Hart and Saunders (1998) highlighted that customer pressure is one of the key motivating factors behind SMBs' ICT innovation adoption. In general, a review of previous studies indicates that most SMB ICT adoption comes as a result of this pressure (Carmichael et al., 2000; Kula \& Tatoglu, 2003; Ifinedo, 2011). At least half of the adults around the world use SNSs, and Jordan was placed no.1 on a Pew Research Center survey of adult Internet users and smartphone owners who use SNSs (Poushter, 2016). This - in line with the network externalities theory-suggests that community demand is a potential factor for SNS adoption among businesses in Jordan.

Competitive Pressure: Competitive pressure refers to the kind of pressure exerted on businesses by their industry competitors that pushes the adoption of new ICT innovation as a trade-off for maintaining its competitiveness (Martins, Gonçalves, Oliveira, Cota, \& Branco, 2016; Ifinedo, 2011). Looi (2005) viewed external pressure as pressure from competitors resulting in environmental uncertainty and leading to an increase in industries' innovation adoption. SMBs' adoption of ICT innovation may be a result of pressure from their customers, partners, and competitors (Poon \& Swatman, 1999; Hart \& Saunders, 1998). Gatignon and Robertson (1989) argued that 
intense competition between businesses pushes them to look for new ways of promoting themselves, like ICT adoption. This factor may be one of the better predictors of ICT innovation acceptance (Gatignon \& Robertson, 1989; Looi, 2005; Jeyaraj, Rottman, \& Lacity, 2006; Chong \& Pervan, 2009; Huang, Janz, \& Frolick, 2008).

\subsection{Barriers to SNS Adoption}

Privacy and Security Concerns: Privacy and security are two main issues that are usually linked to SNS usage. Teo, Ranganathan, \& Dhaliwal (2006) found that security was an essential factor affecting ICT innovation implementation (i.e., e-commerce); hackers breaking into companies' systems play a negative role. As a result of this concern, some firms do not encourage e-commerce. In addition, some firms believe that the basic structures of e-commerce cannot guarantee safety and protection. When it comes to privacy, Messerschmidt and Hinz (2013) wrote that the use and adoption of any given technology depend on its privacy level. They also stated that a company's level of adoption depends on to what extent this technology is reliable and trustworthy. Martins et al. (2016) found that even when companies are aware of SNSs' high level of security, they still have concerns about accepting the risks of adopting new technologies.

Firm Readiness: Iacovou, Benbasat, and Dexter (1995) define organizational readiness as "the availability of the needed organizational resources for technology adoption” (p. 467). Zhu and Kraemer (2005) suggested that technology readiness involved basic technological structures, technical skills, and appropriate systems. Mehrtens, Cragg, \& Mills (2001) and Zhu et al. (2003) argued that the readiness of a business - both physically and in terms of ICT knowledge - was a key factor in ICT adoption. Iacovou et al. (1995), Al-Qirim (2008), and Ramdani, Kawale, \& Lorenzo (2009) discussed this factor from a financial point of view, as well as organizational IT sophistication and expertise. Many other studies showed that SMBs' possession of previous expertise had a positive relationship with adopting new ICT innovations (Cragg \& King, 1993; Chwelos, Benbasat, \& Dexter, 2001; Caldeira \& Ward, 2002).

Low Level of Awareness: Awareness, which is essential for technology adoption, refers to the extent to which a target population is conscious of an innovation and has a general idea of what it entails (Schmidt, Johnston, Arnett, Chen, \& Li, 2008). Several studies investigated the impact of awareness on the adoption of e-commerce in general (e.g., see Molla \& Licker, 2005; Dinev \& Hu, 2007). Molla and Licker (2005) studied ICT innovation adoption of e-commerce in developing countries. The study showed that firms in developing countries might be late in adoption of new ICT innovations because those firms were not aware of the benefits. As a result, they would not take the risk of adopting new technology. SNSs fall into the category of new ICT innovation, which means that firms may not be fully aware of their benefits.

Negative Comments and Reviews: The main element of this category is word of mouth, which Hennig-Thurau, Gwinner, Walsh, \& Gremler (2004) defined as the negative or positive feedback available to the public via the Internet, given by potential, current, or past consumers about a product or service provided by a company. Through a survey, Werbler and Harris (2008) found that $61 \%$ of respondents confirmed their preference of consulting online reviews, blogs, and consumers' feedback before purchasing new products or services. Some studies focused on the influence of negative feedback on consumers' perceptions. MessageLabs (2007) stated that negative comments posted by staff were easy to find online. Park and Lee (2009) concluded that negative feedback had a stronger influence than positive. Some SMBs fear the damage that may result from negative feedback and, as a result, SMBs might choose not to use SNSs.

Regulatory Concerns: Martins et al. (2016) defined regulatory concerns as the legal protection concerns regarding online business or legislation gaps. According to Haywood (1981), regulatory concerns may affect the use of technology. Regulatory concerns are divided into taxation, legal protection, and business law support (Hsu et al., 2006). Several studies investigated the connection between regulatory concerns and innovation and to what extent those concerns affected innovation (e.g., Kuan \& Chau, 2001; Haywood, 1981). Rationally speaking, government initiatives and activates are essential components of ICT use, making it unlikely for businesses to be left entirely unprotected. Regulatory concerns may exist regarding SNS diffusion among SMBs, especially in developing countries, which usually lag behind in formulating regulations for emerging technologies.

Top Management Belief: Several studies have shown that top management support plays a vital role for SMBs in adopting new ICT innovations (e.g., see Grover, 1993; Sila, 2013; Jeyaraj et al., 2006; Ramdani et al., 2009). Ramdani et al. (2009) found that the manager's point of view affects which systems enterprises adopt. Walsh (1988) showed that the development of top management's "belief structure" is affected by the environment on which managers base their inferences. These beliefs play a big role in the organizational strategies, decisions, and behaviors of these managers (Shrivastava, 1983). Other studies, such as Hambrick and Mason (1984), suggest that top management's values and cognitive bases reflect organizational choices. Either way, there is a clear 
relationship between the top management's beliefs and their decisions about ICT innovation.

\section{Methodology}

\subsection{Research Design}

The prominent research method in research designs for adoption and diffusion is a quantitative approach using questionnaires (Williams, Dwivedi, Lal \& Schwarz, 2009; Wang, Fu \& Duan, 2011). Rogers (2003), however, preferred diversity in research design over extensive usage of a one-go survey, in order to avoid any inadequacy in research designs. Wang et al. (2011) stated that to get a better understanding of the complicated and emerging issues included in ICT adoption and diffusion, new research should be conducted to investigate other theories. Wang et al. (2011) also held that more qualitative research, including interviews and action research, should be supported.

The specific objective of this study was to investigate the determinants of SNS decision-making by SMBs and to what extent each determinant affects these decisions. This study therefore conducted qualitative research to achieve deeper analysis of the factors. Open-ended surveys are a form of data collection for qualitative research, generally in the form of a text box in a survey (SurveyMonkey, 2017). This type of question has the necessary flexibility to fully extract respondents' opinions, and the results of this research can pave the way for more empirical quantitative studies. As Johnston (2014) suggested, “. . . open-ended questions also enable the researcher to follow the narrative of thought of respondents and to gauge the respondents' intensity of thought as they express their thoughts and ideas in their own words" (p. 26). To explore the impact of motivating factors and barriers to SMBs' adoption of SNSs while remaining time-efficient and cost-effective, the researcher chose to use an online qualitative survey.

\subsection{Data Collection and Analysis}

In a qualitative study like this one that depends on experts' opinions, the definition of the word expert is essential. The term expert is used by Feigenbaum and McCorduck (1983) to refer to a person inferential and rooted in experiential knowledge that was built through a repertory of working hours in combination with academic knowledge. The opinions of experts who use their expertise and ability to answer research questions is of great value (Arlene \& Kosecoff, 1985). Experts chosen for this study belong to various social and economic contexts and work as social media strategists, client servicing managers at digital marketing agencies, and freelancers. In addition, directors of digital media in public and private organizations. Experts who works with social media agencies or as a freelance usually deal with more than two SMBs clients; while directors of digital media in public and private organizations usually work on full time basis for one organization; for a full list, see Table 1 . The experts selected to participate in the research are key to our results because the study is based on their opinions (Ashton, 1986; Bolger \& Wright, 1994; Parente et al., 1994). According to Okoli and Pawlowski (2004) to verify expert panels' reliability, there are some fundamental points researchers need to consider. First, they must identify experts' skills, topics of interest, and SNS knowledge. Second, the selected experts' profiles must relate to the identified topics. Thus, in this study, the experts were selected using a LinkedIn profile search. Jordan as the place of work was an essential condition.

The researcher first conducted a pilot study with five experts to verify whether the questions were clear in their intent and meaning. The questions were revised accordingly. A set of 24 experts participated in this study. Invitations containing the link to the online survey were sent to participants who manage firms' official pages and profiles on SNSs, and accordingly, the researcher received a clear idea about what makes firms adopt or choose not to adopt SNSs in their businesses. Respondents were encouraged to complete the survey in a quiet environment where they were able to concentrate without interruption. In the first section of the survey, the social media specialists were asked about, how many SMBs they served and how SMBs use SNSs in their businesses in general (Table 1, Table 2). In table 2, experts were allowed to choose more than one option. In the second main section of the survey, respondents were asked to select up to three choices from a list of the main motive factors and barriers identified by the literature as influences on SMBs' decision-making, and then to provide, in the box, their opinions about each factor they selected.

According to Miles and Huberman (1994), the analysis procedure is divided into three steps: "data reduction," "data display," and "conclusion drawing/verification." In this research project, data management and analysis followed this path. The main purpose for summarizing collected data is condensing it (Robson, 2002; Saunders, Lewis \& Thornhill, 2007), but data analysis focuses on organizing it for the sake of drawing conclusions from it.

The findings of the open-ended surveys were used to refine the initial framework model as well as show the reality of SNS adoption in SMBs in Jordan. This kind of research is useful for understanding how SNS experts feel and think about SNS adoption based on their experience. An exploratory qualitative study makes forming flexible 
discussion channels with the participants easier. The discussion had a methodological advantage in that experts were anonymous and not dominated by any singular opinions.

\section{Findings and Discussion}

Table 1 presents the results obtained from the survey for the number of SMBs that have social media specialists to supervise their accounts on SNSs. OF the social media specialists, $29.17 \%$ (7 individuals) supervise from 1 to 2 SMBs; 17 specialists, or $70.83 \%$, supervise more than 3 SMBs.

Table 1. Number of SMBs with Experts Supervising Their Sites on SNSs

\begin{tabular}{lll}
\hline Answer Choices & Responses & \\
\hline 1-2 SMBs & $29.17 \%$ & 7 \\
> 3 SMBs & $70.83 \%$ & 17 \\
& Answered & 24 \\
\hline
\end{tabular}

Table 2 shows the summary statistics for the most prominent uses of SNSs by the companies. There are three answer choices: advertising and marketing, making sales online, and after-sales services and support. The results show that the highest percentage of SNS use is for advertising and marketing (95.83\%, or 23 responses). In comparison with the other choices, this is rather a remarkable result. The percentage of SNS use for making sales online is $33.33 \%$, as it is for the after-sales services and support choice. This indicates that most SMBs in Jordan use SNSs primarily for delivering their customers more information about products and their benefits, and perhaps for introducing or reminding customers about the brand itself.

Table 2. What Are the Most Prominent Uses of SNSs by SMBs?

\begin{tabular}{lll}
\hline Answer Choices & Responses \\
\hline Advertising and marketing & $95.83 \%$ & 23 \\
Making sales online & $33.33 \%$ & 8 \\
After-sales services and support & $33.33 \%$ & 8 \\
\hline
\end{tabular}

\subsection{Motivation}

The chart (Figure 2) shows the main motivating factors of using SNSs in SMBs. The 17 respondents believed that relative advantage was the main motivating factor. It was followed by 13 respondents who listed community demand. Interactivity came in third place with 12 participants, and 6 participants believed that pressure from competitors was an important motivating factor. Perceived ease of use, market scope, innovativeness, and alignment with firm business plans were rated the least important factors.

Relative Advantage: One of experts (EXPs)' highest-rated motivations was relative advantage. The most common advantage was the low cost required to use SNSs to reach audiences (EXPs 2, 5, 6, 7, 9, 11, 14, 17, 19, 20, 21, 23 \& 24). According to EXP 23, "For a small company, the main goal is cost reduction." EXP 24 cited the benefits of digital marketing due to the low costs, in addition to the advantage of having more complete and easier coverage, whereas (EXP 7) sees that the main goal is to have a bigger coverage at a lower cost. Whether to provide followup services (EXP 3), reaching target audiences in a more effective and innovative way (EXPs 9, 12), or reaching the highest number of agents possible in a shorter time and less costs (EXP 17) SNS platforms are more effective. According to EXP 9, "Through social media platforms, you can reach the targeted audience with low cost unlike other advertising methods such as radio and television, which makes e-marketing an effective and better method." SMBs are more likely to adopt new innovations once they perceive them to offer a relative advantage (Rogers, 2003). EXP 17 explained that SNSs enable SMBs to change their marketing theme constantly, which gives firms an opportunity to refresh their campaigns in a shorter time and less costs. Others EXPs like EXPs 9, 11, 14, and 20 highlighted that using SNSs had more benefits in e-commerce and advertising than traditional methods. 


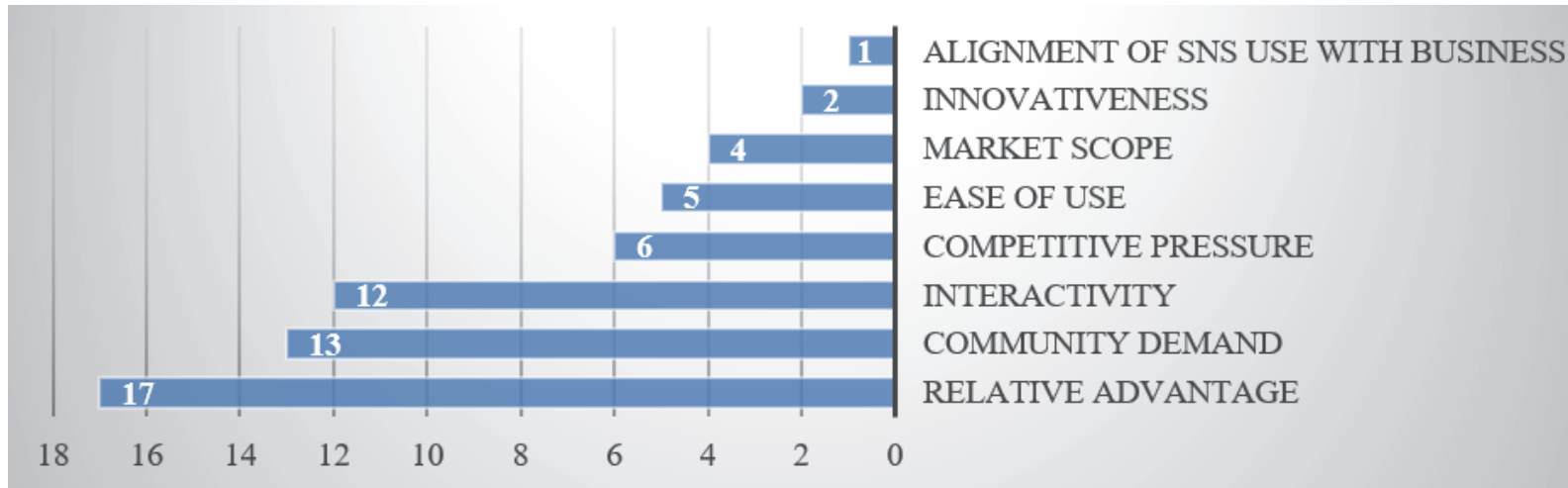

Figure 2. Motivation Factors

Community Demand: Most EXPs chose community demand as a motivation for using SNSs because most users have at least one form of SNS platform that they use (EXP 1 and 2). Exp 10 states that the number of Internet users has increased in Jordan, while EXP 5 stated that the percentage of SNS users is increasing. In fact, international statistics indicate that the percentage of active SNS users among adult Internet users in Jordan is of $90 \%$, thus surpassing many developed countries like the United States (71\%), Russia (85\%), and France (57\%) (Poushter, 2016). EXP 4 stated that "in Jordan, the number of Facebook users is significantly high' almost 5.300.000, [so] successful promotion campaigns could be achieved through SNS advertisements." EXP 5 stated that due to the increased SNS users, promoting products and services using SNSs makes delivering accurate product information easier. and EXP 16 argued that it offers companies the opportunity to discover people's needs. According to EXP 13, "Companies and firms must be present on social media platforms due to the increased number of users and their relocation of interactivity in the virtual world." EXP 14 said that "Due to increasing number of [SNS] users every day, companies cannot neglect the users' orientation; thus they have to adapt." As a result, the increasing number of users and the relocation of their interactivity into the virtual world form a new community orientation and demand that businesses cannot neglect.

Interactivity: EXPs 5, 8, 13 and 17 explained that using multimedia posts like videos and images to explain product usage or provide information by interacting with the users is more effective than traditional methods. EXPs 1 and 12 said that users found it easier to communicate with the companies through SNS platforms than through other means. Thus, the opportunity to post an image, video, or comment and enabling users to interact with it through commenting and sharing can motivate SMBs to adopt SNSs. EXP 17 stated that SNSs have the ability to change their themes or messages easily and via many mediums to deliver marketing messages and concepts to the customers. Social media platforms allows the companies to directly contact customers and engage them in group discussions (EXP 19). According to EXPs 20 and 24, SNSs consist of images, sounds, and videos, which are powerful influences on the way customers perceive and understand the intended ideas. EXPs 22 and 23 believe that the speed and easiness of spreading content are factors that affect SNS adoption positively.

\subsection{Barriers}

The chart (Figure 3) shows the main barriers factors of using Social Network Sites in SMBs. From this chart, it can be noticed that top management belief was highly chosen. 17 participants belief that top management belief is the main barrier for using SNS in SMBs. Level of awareness about SNS, firm readiness and negative comments/ reviews come in the second, third and fourth places in order. Whereas 4 participants selected regulation concerns and 3 selected privacy and security. None of the respondents chose the barrier "no trust in SNS" as a significant one.

Top management belief: One of the barrier factors in SNS adoption is the top management belief, which is manifested in two major categories: either lack of technological information and awareness of SNS benefits, or the perceived idea that SNS is of no use or their lack of interest or desire of change. EXP 1, 2, 3,4,14 were sure that the CEO's insufficient information regarding SNS and its way of function is a top factor in refusing SNS adoption. Most of the firms' CEOs do not give much attention or they start at later stage which negatively affects their business (EXP 11). EXP 5, 9,11,13,17 and 18 indicated that some managers believe that SNS adoption is of no use and that the presence of sales and accounting employees is enough (EXP 9). EXP 13 said that managers are not convinced of the financial return of digital marketing with less cost and they believe that direct communication 
with the users is more effective. EXP $(17,19)$ state that if those who are responsible in the companies such as managers and CEOs despise SNS or perceive it as a waste of time then, they will not know the advantages of SNS, especially the ones who are old in age (EXP 17). Some managers are not even aware of the SNS which causes a great problem for the marketing department (EXP 20).

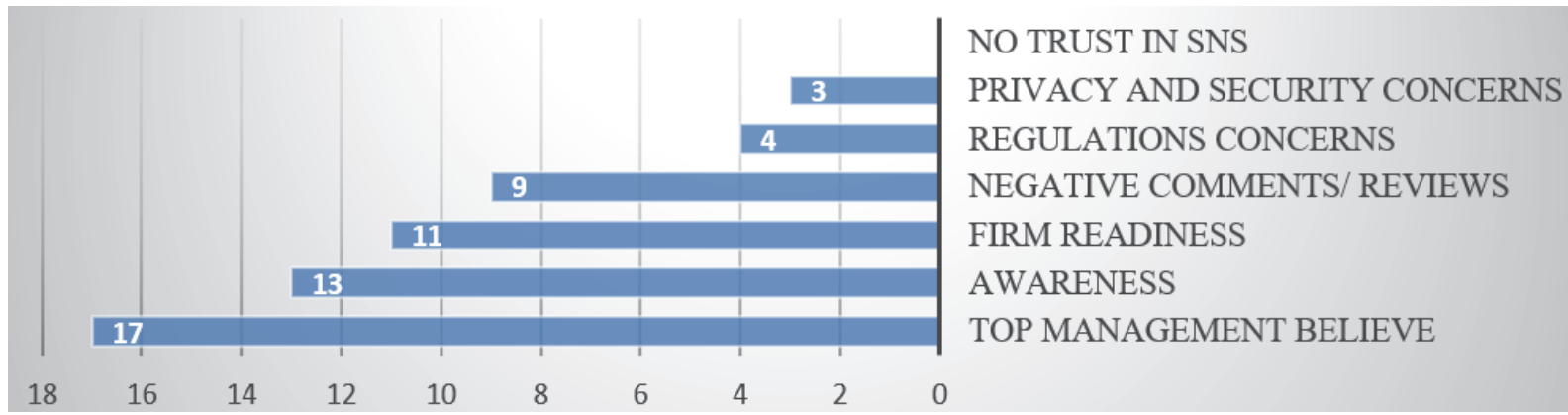

Figure 3. Barriers

Readiness: Most EXPs connect readiness with the use of a social media specialist. EXP 3 states that although the number of people working in this field is quite high, there is no experience of competencies, thus many companies prefer not to adventure in it. EXP 4, 6, 7 and 11 argue that due to the lack of awareness towards the benefits of SNS platforms, many companies would have to hire an expert or work with an external specialist which will add to its cost, thus lowering the level of SNS adoption choice by SMBs while EXP 15 believes that companies are not fully equipped for this function with the means needed and well-formed plan for using SNSs in order to succeed. EXP 19 states that many companies do not make the effort to sign contracts with experts and they do not desire to invest in support tools. Some companies get disappointed with the results of SNS, thus, they will lose faith in SNS and stop using it (EXP 21). The lack of experts in some companies is another burden (EXP 22). Understandably, readiness factor is a common barrier that usually hinders small businesses from ICT innovation adoption. EXP 24 states that due to the development of the electronic marketing, managers find it difficult to establish a specialized department.

Fear of negative comments and reviews: In this field, negative comments and reviews could affect the company's image negatively. EXP 11 and 13 believe that the negative comments left by users could damage the company's image if it is not handled properly. EXP 13 believes that a successful digital marketing director can use these errors in favor of the company; to attract the attention of the customers in a creative way, while EXP 5 states that the advertisements posted in SNS platforms need a detailed study by a group of experts to exclude any errors that may occur since these will be available for users of all ages, thus the fear of these errors merging after the advertisement has been launched prevent SMBs from SNS adoption. EXP 10 states that lack of trust increases the barrier of fear, which in return affects SNS adoption by SMBs negatively.

Awareness: The lack of knowledge regarding the importance of SNS and how to develop it in the right way leads to the perceived barriers. Some firms lack the ability to create successful plans for the social media networks (EXP 3). EXP 4 and 9 think that the need of a SNSs expert is one of the barriers that make companies uncertain of the benefits of SNSs; such as the costs needed for developing a successful social media channel, or the experts' salary which is perceived by many CEO's as too high just for managing an SNS platform for the company. EXP 4 perceives the ignorance of companies of SNSs platforms' benefits as a major problem, especially in an era where most of the internet users are on SNSs. EXP 6 thinks that this uncertainty towards SNS adoption comes from the poor understanding of modern tools and techniques. According to EXP 19, some companies believe that SNSs are complementary for the traditional marketing methods and they seek applying similar strategies for the traditional ones. Other companies perceive SNS as means of entertainment (EXP 21) or do not even trust it (EXP 22, 23).

\section{Variations in Experts' Opinions}

It's worth mentioning that deeper comparison between experts opinion could reveal some variation in their opinions, which in turn could pave the way for more investigations. For instance, firms' concern regarding the cost lies in the fact that the costs of social media outweigh the potential benefits for our company (EXP 5). EXP 12 believes that some clients are committed for three months only and they cancel the contract or divert the money somewhere else such as vouchers which comes as an obstacle for the company. EXP. 9 argues that this occurs as a result for misunderstanding of the online marketing on the SMBs part, and they confuse it with the basic concept 
of companies in the marketing field. EXP 5 disagrees since he believes that when a professional expert handles the social media marketing, the income will overcome the costs.

Most experts did agree upon the fact that SNS provide multimedia tools such as; video, audio and pictures, which enable conveying the companies message in an easier and more attractive way (Exp 5,8 and 13), while others (Exp 1, 6, 12, 19 and 24) did not perceive interactivity as the multimedia tools, rather they believe that SNS paves the way to communicant and connect with current and potential customers in a more direct and open manner, enabling others to comment and take part in the discussion. Exp 17 and 22 see that campaigns based on SNS have a more flexible range of changing the content or message intended. This disparity in experts' point of view regarding interactivity factor is due to the differences in the company's need and marketing plan, whether base on SNS fully or just as an additional support.

Some experts elect the easiness of SNS use as a main factor for SNS adoption. Exp 21 believes that due to the ease of use, in many cases the managers think that firms SNS page supervision can be processed by anyone. Thus, according to this statement, there is no need for social media experts or agency. This case can rise many debates since looking at the barriers sides, some experts state that a lot of SMBs postponed adopting SNSs due to the lack of social media experts e.g. Exp3. This variation in experts opinions could partially explained that different SMB have different level of need to SNSs. Some SMBs may need SNSs for simple marketing activities, while other SMBs are seeking for advance promotion campaigns for their products and services. Thus, an ambiguity is created regarding this factor, and more research with more detailed SMBs classification could lead for further results. Finally, one of the differences between experts regarding the regulatory concern is the fear of the absence of settled laws that regulate using the social network sites in Jordan (expert 24). According to expert 24, the problem relies in the firms' concern of the online marketing that is not governed by certain laws which makes it easier to violate or copy the firm product by the competing companies. Expert $(13,23)$ are concerned with the issue of copying ideas and products as a result for employees' lack of experience in using pictures or items illegally leads the company to be legally questioned. And this, according to expert 13, forms a big concern for some SMBs managers in terms of using social network in their business. EXP 12 believes that sometimes they get many rejected advertisements because social media platforms such as Facebook \& Instagram have their own regulations that are changeable and sometimes unpredictable which wastes their time and efforts. Again, it can be noted that different firms with different interests and activities could expose the firms to different regulation concerns which therefore, call for more examinations.

\section{Discussion}

The research results are summarized in Table 3, based on the evidence collected. Discussion of the results will be presented in this section. Despite the high percentage of Jordanian active users on SNSs, discussions of SNSs adoption among SMBs in Jordan have not reached the level of clarity of more mature areas of ICT innovation adoption. Based on network externalities theory, this research project offers evidence that environmental factor such as community demand factor is significant. Accordingly, SNSs adoption is not limited to factor related to the organizational and technological contexts. Motivation and barrier framework in this study has proven holistic enough to explore SNSs adoption. Among the initial factors, this study has been able to demonstrate the impact of 7 of them on SMBs.

Fresh ICT innovations are generally expected to bring major advantages and add value to a firm. For that reason, relative advantage is regularly used as a main determinant in technology adoption literature (Alshamaila_et al., 2013). Perceived ease of use, market scope, and competitive pressure are not always strong enough motivators for technology implementation. The increasing number of SNS users and the relocation of their interactivity into the virtual world (EXP 14) have led to changes in local community shopping behavior. As a result, community demand has emerged as a key environmental factor that pushes SMBs to adopt SNSs. For that reason, more understanding and more awareness among SMB managers about local community trends in SNSs are important to the adoption decision. This finding highlights the significant role of social media marketing companies and social media experts in raising awareness and engaging customers. Even though SMBs are often initially attracted to SNSs by the interactive features they provide, top management belief is still a key factor in SNS rejection. Low awareness levels and fear of negative comments and reviews are the main concerns of businesses and managers in supporting SNS adoption. SMBs may have concerns about sudden, unpredictable changes in SNSs' strategies that could negatively affect their image. Managers may also feel that their companies are not yet ready for SNS adoption. In fact, managers' fears and concerns can sometimes be rational. Social media experts and social media marketing firms must make more efforts to increase awareness among managers about the benefits of using SNSs for businesses and how to deal with negative reviews and comments. 
Table 3. Summary of Findings

\begin{tabular}{lll}
\hline Factor & Support & Experts \\
\hline Motivations & Motivations & Motivations \\
Relative Advantage & High & $2,3,5-7,9-12,14,15,17,19-24$ \\
Ease of Use & -- & $10,15,20-22$ \\
Interactivity & High & $1,5,6,8,12,13,17,19,20,22-24$ \\
Innovativeness & -- & 2,15 \\
Alignment Business Strategic Plan & -- & 16 \\
Market Scope & -- & $3,6,7,24$ \\
Community Demand & High & $1,2,4,5,7,10,13,14,16,19,21,23,24$ \\
Competitive Pressure & -- & $4,11,13,17,18,22$, \\
\hline Barriers & Barriers & Barriers \\
\hline Readiness & High & $3,4,6,7,8,11,15,19,21,22,24$ \\
Privacy and Security Concerns & -- & $2,10,15$ \\
Firm Awareness & High & $1,3,4,6,8,9,10,18,19,21,22,23,24$ \\
Negative Comments and Reviews & High & $5,8,10,11,13,14,20,21,24$ \\
Trust in SNS Technology and Participants & -- & \\
Regulatory Concerns & -- & $12,13,23,24$ \\
Top Management Belief & High & $1,2,3,4,5,7,9,11,13,14,16,17,18,19,20,22,23$ \\
\hline
\end{tabular}

\section{Conclusion}

SNSs offer opportunities to SMBs to get their message out as a result of their unique interactive features. But for all of their potential, there's still a lot of vagueness out there among business about SNSs. SNSs still remain under examined by researchers and underused by firms as a tool for improving business strategies. In fact, many firms have been slow to adopt new technologies because of perceived barriers and challenges. In the case of SNS adoption among firms, issues such as firms' readiness, top management belief, and fear of negative comments and reviews could seriously inhibit usage among SMBs. This research project aims to explore the main motivations and barriers for adoption of SNSs. This study provides significant implications and benefits to the researchers, managers, and social media companies in formulating improved strategies for SNS adoption. Social media marketing firms may help to clarify how SMBs can deal with negative reviews and comments, which, in turn, can affect SMBs' confidence. In addition, social media experts need to raise awareness about the benefits of SNSs to SMBs that are unsure about whether social media can help their businesses. Experts need to help SMBs reap the advantages that SNSs provide such as interactivity and capitalize on the fact that the great percentage of shoppers stay on SNSs for long periods of time. Although this approach is useful for business-related decision analysis, the scope of this study is limited in terms of generalizability. However, these research findings provide the following insights for future research. Further work could build on this study by both validating the existing factors identified in this research project and exploring whether other determinants emerge. Further qualitative and quantitative study to examine SNS adoption in different industries and sectors in other countries is recommended.

\section{Acknowledgement}

This work was supported by the Deanship of Academic Research, The University of Jordan.

\section{References}

Ainin, S., Parveen, F., Moghavvemi, S., Jaafar, N. I., \& Mohd Shuib, N. L. (2015). Factors influencing the use of social media by SMEs and its performance outcomes. Industrial Management \& Data Systems, 115(3), 570588. https://doi.org/10.1108/IMDS-07-2014-0205

Al-Qirim, N. (2008). The adoption of eCommerce communications and applications technologies in small businesses in New Zealand. Electronic Commerce Research and Applications, 6(4), 462-473. https://doi.org/10.1016/j.elerap.2007.02.012

Alshamaila, Y., Papagiannidis, S., \& Li, F. (2013). Cloud computing adoption by SMEs in the north east of England: A multi-perspective framework. Journal of Enterprise Information Management, 26(3), 250-275. https://doi.org/10.1108/17410391311325225

Araújo, J. B. D., \& Zilber, S. N. (2016). What factors lead companies to adopt social media in their processes: Proposal and test of a measurement model. BBR. Brazilian Business Review, 13(6), 260-290. 
http://dx.doi.org/10.15728/bbr.2016.13.6.5.

Arlene, F., \& Kosecoff, J. (1998). How to Conduct Surveys: A step by step guide.

Armstrong, C. P., \& Sambamurthy, V. (1999). Information technology assimilation in firms: The influence of senior leadership and IT infrastructures. Information systems research, 10(4), 304-327.

Ashton, R. H. (1986). Combining the judgments of experts: How many and which ones?. Organizational Behavior and Human Decision Processes, 38(3), 405-414. https://doi.org/10.1016/0749-5978(86)90009-9

Barnett, A. H., \& Kaserman, D. L. (1998). The simple welfare economics of network externalities and the uneasy case for subscribership subsidies. Journal of Regulatory Economics, 13(3), 245-254. https://doi.org/10.1023/A:1008029120462

Bharadwaj, A. S. (2000). A resource-based perspective on information technology capability and firm performance: an empirical investigation. MIS quarterly, 169-196. https://doi.org/10.2307/3250983

Bolger, F., \& Wright, G. (1994). Assessing the quality of expert judgment: Issues and analysis. Decision support systems, 11(1), 1-24. https://doi.org/10.1016/0167-9236(94)90061-2

Broadbent, M., \& Weill, P. (1993). Improving business and information strategy alignment: Learning from the banking industry. IBM systems Journal, 32(1), 162-179. https://doi.org/ 10.1147/sj.321.0162

Burn, J. M., \& Szeto, C. (2000). A comparison of the views of business and IT management on success factors for strategic alignment. Information \& management, 37(4), 197-216. https://doi.org/10.1016/S03787206(99)00048-8

Caldeira, M. M., \& Ward, J. M. (2002). Understanding the successful adoption and use of IS/IT in SMEs: an explanation from Portuguese manufacturing industries. Information Systems Journal, 12(2), 121-152. https://doi.org/ 10.1046/j.1365-2575.2002.00119.x

Carmichael, C., Turgoose, C., Gray, M. O., Todd, C., \& Nadin, S. (2000). Innovation and SMEs: The case of South Yorkshire, UK. Industry and Higher Education, 14(4), 244248.https://doi.org/10.5367/000000000101295147

Chong, S., \& Pervan, G. (2009). Factors influencing the extent of deployment of electronic commerce for smalland medium-sized enterprises. IGI Global. https://doi.org/ 10.4018/jeco.2007010101

Chwelos, P., Benbasat, I., \& Dexter, A. S. (2001). Empirical test of an EDI adoption model. Information systems research, 12(3), 304-321.

Cone (2008). Business in social media study. Retrieved December 14, 2015, from http://onesocialmedia.com/wpcontent/uploads/2010/03/2008_business_in_social_media_fact_sheet.pdf

Cragg, P. B., \& King, M. (1993). Small-firm computing: motivators and inhibitors. MIS quarterly, 47-60. https://doi.org/ 10.2307/249509

Culnan, M. J., McHugh, P. J., \& Zubillaga, J. I. (2010). How large US companies can use Twitter and other social media to gain business value. MIS Quarterly Executive, 9(4).

Daniel, E. M., \& Grimshaw, D. J. (2002). An exploratory comparison of electronic commerce adoption in large and small enterprises. Journal of Information Technology, 17(3), 133-147.

Daniel, F. D. (1989). Perceived usefulness, perceived ease of use, and user acceptance of information technology. MIS quarterly, 319-340. https://doi.org/ 10.2307/249008

Dinev, T., \& Hu, Q. (2007). The centrality of awareness in the formation of user behavioral intention toward protective information technologies. Journal of the Association for Information Systems, 8(7), 386.

Einhorn, M. A. (1993). Biases in optimal pricing with network externalities. Review of Industrial Organization, 8(6), 741-746. https://doi.org/10.1007/BF01024295

Elmazi, I., Vukaj, H., Gega, E., \& Elmazi, L. (2011). Information technology and its effects in SME. The case of Albania. International Journal of Management Cases, 13(4), 291-298. https://doi.org/10.5848/APBJ.2011.00139

Eurostat. (2017). Social media - statistics on the use by enterprises. Retrieved from http://ec.europa.eu/eurostat/statistics-explained/index.php/Social_media__statistics_on_the_use_by_enterprises

Farrell, J., \& Klemperer, P. (2007). Coordination and lock-in: Competition with switching costs and network 
effects. Handbook of industrial organization, 3, 1967-2072. https://doi.org/10.1016/S1573-448X(06)030317

Feigenbaum, E. A., \& McCorduck, P. (1984). The fifth generation (p. 52). London: Pan Books.

Gandal, N., Salant, D., \& Waverman, L. (2003). Standards in wireless telephone networks. Telecommunications Policy, 27(5-6), 325-332. https://doi.org/10.1016/S0308-5961(03)00026-0

Gandomi, A., \& Haider, M. (2015). Beyond the hype: Big data concepts, methods, and analytics. International Journal of Information Management, 35(2), 137-144. https://doi.org/10.1016/j.ijinfomgt.2014.10.007

Garverick, M. L. (2014). Motives and Barriers to Cloud ERP Selection for SMEs: A Survey of Value Added Resellers (VAR) Perspectives. Dissertation, Georgia State University.

Gatignon, H., \& Robertson, T. S. (1989). Technology diffusion: an empirical test of competitive effects. The Journal of Marketing, 35-49. https://doi.org/10.2307/1251523

Grandon, E. E., \& Pearson, J. M. (2004). Electronic commerce adoption: an empirical study of small and medium US businesses. Information \& management, 42(1), 197-216. https://doi.org/10.1016/j.im.2003.12.010

Grover, V. (1993). An empirically derived model for the adoption of customer-based interorganizational systems. Decision sciences, 24(3), 603-640. https://doi.org/10.1111/j.1540-5915.1993.tb01295.x

Hambrick, D. C., \& Mason, P. A. (1984). Upper echelons: The organization as a reflection of its top managers. Academy of management review, 9(2), 193-206. https://doi.org/10.5465/AMR.1984.4277628

Hart, P. J., \& Saunders, C. S. (1998). Emerging electronic partnerships: antecedents and dimensions of EDI use from the supplier's perspective. Journal of Management Information Systems, 14(4), 87-111. https://doi.org/10.1080/07421222.1998.11518187

Haywood, C. F. (1981). Regulation, structure and technological change in the consumer financial services industry. Regulation of Consumer Financial Services. Cambridge, MA: Abt Books, 163-167.

Henderson, J. C., \& Sifonis, J. G. (1988). The value of strategic IS planning: understanding consistency, validity, and IS markets. MIS quarterly, 187-200. https://doi.org/ 10.2307/248843

Hennig-Thurau, T., Gwinner, K. P., Walsh, G., \& Gremler, D. D. (2004). Electronic word-of-mouth via consumeropinion platforms: what motivates consumers to articulate themselves on the internet? Journal of interactive marketing, 18(1), 38-52. https://doi.org/ 10.1002/dir.10073

Hirschman, E. C. (1980). Innovativeness, novelty seeking, and consumer creativity. Journal of consumer research, 7(3), 283-295. https://doi.org/10.1086/208816

Hsu, P. F., Kraemer, K. L., \& Dunkle, D. (2006). Determinants of e-business use in US firms. International Journal of Electronic Commerce, 10(4), 9-45.

Iacovou, C. L., Benbasat, I., \& Dexter, A. S. (1995). Electronic data interchange and small organizations: Adoption and impact of technology. MIS quarterly, 465-485. https://doi.org/ 10.2307/249629

Ifinedo, P. (2011). An empirical analysis of factors influencing Internet/e-business technologies adoption by SMEs in Canada. International Journal of Information Technology \& Decision Making, 10(04), 731-766. https://doi.org/10.1142/S0219622011004543

Jeyaraj, A., Rottman, J. W., \& Lacity, M. C. (2006). A review of the predictors, linkages, and biases in IT innovation adoption research. Journal of Information Technology, 21(1), 1-23.

Jo, S., \& Kim, Y. (2003). The effect of web characteristics on relationship building. Journal of Public Relations Research, 15(3), 199-223. https://doi.org/10.1207/S1532754XJPRR1503_1

Johnston, P. (2014). Exploring New Types of Motives in Social Media (Doctoral dissertation, Kent State University).

Kahn, A. E., \& Shew, W. B. (1986). Current issues in telecommunications regulation: Pricing. Yale J. on Reg., 4, 191.

Kaplan, A. M., \& Haenlein, M. (2010). Users of the world, unite! The challenges and opportunities of Social Media. Business horizons, 53(1), 59-68. https://doi.org/10.1016/j.bushor.2009.09.003

Kelleher, T., \& Miller, B. M. (2006). Organizational blogs and the human voice: Relational strategies and relational outcomes. Journal of Computer-Mediated Communication, 11(2), 395-414. https://doi.org/10.1111/j.10836101.2006.00019.x

Kent, M. L. (2008). Critical analysis of blogging in public relations. Public Relations Review, 34(1), 32-40. 
https://doi.org/10.1016/j.pubrev.2007.12.001

Kietzmann, J. H., Silvestre, B. S., McCarthy, I. P., \& Pitt, L. F. (2012). Unpacking the social media phenomenon: towards a research agenda. Journal of Public Affairs, 12(2), 109-119. https://doi.org/10.1002/pa.1412

Kuan, K. K., \& Chau, P. Y. (2001). A perception-based model for EDI adoption in small businesses using a technology-organization-environment framework. Information \& Management, 38(8), 507-521. https://doi.org/10.1016/S0378-7206(01)00073-8

Kula, V., \& Tatoglu, E. (2003). An exploratory study of Internet adoption by SMEs in an emerging market economy. European Business Review, 15(5), 324-333. https://doi.org/10.1108/09555340310493045

Leung, L., \& Wei, R. (1998). Factors influencing the adoption of interactive TV in Hong Kong: Implications for advertising. Asian Journal of Communication, 8(2), 124-147. https://doi.org/10.1080/01292989809364766

Lin, C. A., \& Jeffres, L. W. (1998). Factors influencing the adoption of multimedia cable technology. Journalism \& Mass Communication Quarterly, 75(2), 341-352. https://doi.org/10.1177/107769909807500209

Liu, Y., \& Shrum, L. J. (2002). What is interactivity and is it always such a good thing? Implications of definition, person, and situation for the influence of interactivity on advertising effectiveness. Journal of advertising, 31(4), 53-64. https://doi.org/10.1080/00913367.2002.10673685

Looi, H. C. (2005). E-commerce adoption in Brunei Darussalam: a quantitative analysis of factors influencing its adoption. Communications of the Association for Information Systems, 15(1), 3.

Marcati, A., Guido, G., \& Peluso, A. M. (2008). The role of SME entrepreneurs' innovativeness and personality in the adoption of innovations. Research Policy, 37(9), 1579-1590. https://doi.org/10.1016/j.respol.2008.06.004

Martins, J., Gonçalves, R., Oliveira, T., Cota, M., \& Branco, F. (2016). Understanding the determinants of social network sites adoption at firm level: A mixed methodology approach. Electronic Commerce Research and Applications, 18, 10-26. https://doi.org/10.1016/j.elerap.2016.05.002

Martins, J., Goncalves, R., Pereira, J., Oliveira, T., \& Cota, M. P. (2014, June). Social networks sites adoption at firm level: A literature review. In Information Systems and Technologies (CISTI), 2014 9th Iberian Conference on (pp. 1-6). IEEE. https://doi.org/ 10.1109/CISTI.2014.6876910

Mason, R., \& Valletti, T. M. (2001). Competition in communication networks: pricing and regulation. Oxford Review of Economic Policy, 17(3), 389-415. https://doi.org/10.1093/oxrep/17.3.389

Mehrtens, J., Cragg, P. B., \& Mills, A. M. (2001). A model of Internet adoption by SMEs. Information \& management, 39(3), 165-176. https://doi.org/10.1016/S0378-7206(01)00086-6

MessageLabs (2007a). Online social networking: the employer's dilemma. Retrieved 25 March 2008, from http://downloads.messagelabs.com/silikonuk/wss_whitepaper_socialnetworking_legal_a4_final.pdf

MessageLabs (2007b), "Social networking: a brave new world or revolution from hell? Retrieved 27 February 2008, from http://i.i.com.com/cnwk.id/html/iop/messagelabs_socialnetworking.pdf

Messerschmidt, C. M., \& Hinz, O. (2013). Explaining the adoption of grid computing: An integrated institutional theory and organizational capability approach. The Journal of Strategic Information Systems, 22(2), 137-156. https://doi.org/10.1016/j.jsis.2012.10.005

Miles, M. B., \& Huberman, A. M. (1994). Qualitative data analysis: An expanded sourcebook. sage.

Mirchandani, D. A., \& Motwani, J. (2001). Understanding small business electronic commerce adoption: An empirical analysis. Journal of Computer Information Systems, 41(3), 70-73.

Molla, A., \& Licker, P. S. (2005). Perceived e-readiness factors in e-commerce adoption: An empirical investigation in a developing country. International Journal of Electronic Commerce, 10(1), 83-110.

NETconsent Limited (2004), Employee Internet Access: Effective Management of the Whitepapers Organisational Risk, Retrieved 27 February 2008, from www.netconsent.com/Resources/Whitepapers.htm

Nobre, H., \& Silva, D. (2014). Social network marketing strategy and SME strategy benefits. Journal of Transnational Management, 19(2), 138-151. https://doi.org/10.1080/15475778.2014.904658

Odoom, R., Anning-Dorson, T., \& Acheampong, G. (2017). Antecedents of social media usage and performance benefits in small-and medium-sized enterprises (SMEs). Journal of Enterprise Information Management, 30(3), 383-399. https://doi.org/10.1108/JEIM-04-2016-0088

Okoli, C., \& Pawlowski, S. D. (2004). The Delphi method as a research tool: an example, design considerations 
and applications. Information \& management, 42(1), 15-29. https://oi.org/10.1016/j.im.2003.11.002

Panzar, J. C., \& Wildman, S. S. (1995). Network competition and the provision of universal service. Industrial and Corporate Change, 4(4), 711-719. https://doi.org/10.1093/icc/4.4.711

Parente, F. J., Anderson, J. K., Myers, P., \& O'brien, T. (1984). An examination of factors contributing to Delphi accuracy. Journal of Forecasting, 3(2), 173-182. https://doi.org/10.1002/for.3980030205

Park, C., \& Lee, T. M. (2009). Information direction, website reputation and eWOM effect: A moderating role of product type. Journal of Business Research, 62(1), 61-67. https://doi.org/10.1016/j.jbusres.2007.11.017

Parveen, F. (2012, July). Impact Of Social Media Usage On Organizations. In PACIS (p. 192).Peters, K., Chen, Y., Kaplan, A. M., Ognibeni, B., \& Pauwels, K. (2013). Social media metrics-A framework and guidelines for managing social media. Journal of Interactive Marketing, 27(4), 281-298. https://doi.org/10.1016/j.intmar.2013.09.007Get rights and content

Poon, S., \& Swatman, P. M. (1997). Internet-based small business communication: Seven Australian cases. Electronic Markets, 7(2), 15-21.

Poushter, J. (2016). Smartphone ownership and internet usage continues to climb in emerging economies. Pew Research Center, 22.

Proceedings of the 39th Annual Hawaii International Conference on (Vol. 6, pp. 127a-127a). IEEE. Huang, Z., Janz, B. D., \& Frolick, M. N. (2008). A comprehensive examination of Internet-EDI adoption. Information Systems Management, 25(3), 273-286.

Ramdani, B., Kawalek, P., \& Lorenzo, O. (2009). Predicting SMEs' adoption of enterprise systems. Journal of Enterprise Information Management, 22(1/2), 10-24. https://doi.org/10.1108/17410390910922796

Robson, C. (2002). Real World Research: A Resource for Social Scientists and Practitioner-Researchers (2nd ed). Blackwell Publishing: Oxford, UK.

Rogers, E. M. (2003). Diffusion of innovations. Free Press. New York, 551.

Rogers, E. M., \& Shoemaker, F. F. (1971). Communication of Innovations; A Cross-Cultural Approach.

Rohlfs, J. (1974). A theory of interdependent demand for a communications service. The Bell Journal of Economics and Management Science, 16-37. https://doi.org/ 10.2307/3003090

Saffer, A. J., Sommerfeldt, E. J., \& Taylor, M. (2013). The effects of organizational Twitter interactivity on organization-public relationships. Public Relations Review, 39(3), 213-215. https://doi.org/10.1016/j.pubrev.2013.02.005

Saunders, M. N. K., Lewis, P., \& Thornhill, A. (2000). Research Methods for Business Students: Lecturers' Guide.

Schmidt, M. B., Johnston, A. C., Arnett, K. P., Chen, J. Q., \& Li, S. (2008). A cross-cultural comparison of US and Chinese computer security awareness. Journal of Global Information Management, 16(2), 91. https://doi.org/10.4018/jgim.2008040106

Shah Alam, S., Ali, M. Y., \& Mohd-Jani, M. F. (2011). An empirical study of factors affecting electronic commerce adoption among SMEs in Malaysia. Journal of Business Economics and Management, 12(2), 375-399.

Shapiro, C., Varian, H. R., \& Becker, W. E. (1999). Information rules: a strategic guide to the network economy. Journal of Economic Education, 30, 189-190.

Shrivastava, P. (1983). A typology of organizational learning systems. Journal of management studies, 20(1), 728. https://doi.org/ 10.1111/j.1467-6486.1983.tb00195.x

Shy, O. (2001). The economics of network industries. Cambridge University Press.

Sila, I. (2013). Factors affecting the adoption of B2B e-commerce technologies. Electronic commerce research, 13(2), 199-236.

Smith, B. G. (2010). Socially distributing public relations: Twitter, Haiti, and interactivity in social media. Public Relations Review, 36(4), 329-335. https://doi.org/10.1016/j.pubrev.2010.08.005

Squire, L. (1973). Some aspects of optimal pricing for telecommunications. The Bell Journal of Economics and Management Science, 515-525. https://doi.org/ 10.2307/3003051

Sundar, S. S., Kalyanaraman, S., \& Brown, J. (2003). Explicating web site interactivity: Impression formation effects in political campaign sites. Communication Research, 30(1), 30-59. https://doi.org/10.1177/0093650202239025 
Surveymonkey. (2017). Conducting Qualitative Research. Retrieved from https://www.surveymonkey.com/mp/conducting-qualitative-research/

Sweetser, K. D., \& Metzgar, E. (2007). Communicating during crisis: Use of blogs as a relationship management tool. Public Relations Review, 33(3), 340-342. https://doi.org/10.1016/j.pubrev.2007.05.016

Teo, T. S., Ranganathan, C., \& Dhaliwal, J. (2006). Key dimensions of inhibitors for the deployment of web-based business-to-business electronic commerce. IEEE Transactions on engineering Management, 53(3), 395-411. https://doi.org/ 10.1109/TEM.2006.878106

Tiago, M. T. P. M. B., \& Veríssimo, J. M. C. (2014). Digital marketing and social media: Why bother? Business Horizons, 57(6), 703-708. https://doi.org/10.1016/j.bushor.2014.07.002

Walsh, J. P. (1988). Top management turnover following mergers and acquisitions. Strategic Management Journal, 9(2), 173-183. https://doi.org/ 10.1002/smj.4250090207

Wang, R., Fu, Z., \& Duan, Y. (2011) Management and Service Science (MASS), 2011 International Conference on. 12-14 Aug. 2011.

Wanyoike, D. M., Mukulu, E., \& Waititu, A. G. (2012). ICT attributes as determinants of e-commerce adoption by formal small enterprises in urban Kenya. International Journal of Business and Social Science, 3(23).

Werbler, C., \& Harris, C. (2008). Online consumer reviews significantly impact consumer purchasing decisions, new opinion research corporation survey finds. Retrieved Oct, 6, 2010.

Williams, M., Dwivedi, Y., Lal, B., \& Schwarz, A. (2009). Contemporary trends and issues in IT adoption and diffusion research. Journal of Information Technology, 24(1), 1-10. https://doi.org/10.1057/jit.2008.30

Xu, M., Rohatgi, R., \& Duan, Y. (2007). E-business adoption in SMEs: some preliminary findings from electronic components industry. International Journal of E-Business Research, 3(1), 74. https://doi.org/10.4018/jebr.2007010105

Yannelis, D. (2001). On the simple welfare economics of network externalities. International Journal of Social Economics, 28(4), 344-348. https://doi.org/10.1108/EUM0000000005401

Zeiller, M., \& Schauer, B. (2011, September). Adoption, motivation and success factors of social media for team collaboration in SMEs. In Proceedings of the 11th international conference on Knowledge Management and Knowledge Technologies (p. 4). ACM.

Zhu, K., \& Kraemer, K. L. (2005). Post-adoption variations in usage and value of e-business by organizations: cross-country evidence from the retail industry. Information systems research, 16(1), 61-84.

Zhu, K., Kraemer, K., \& Xu, S. (2003). Electronic business adoption by European firms: A cross-country assessment of the facilitators and inhibitors. European Journal of Information Systems, 12(4), 251-268.

\section{Copyrights}

Copyright for this article is retained by the author(s), with first publication rights granted to the journal.

This is an open-access article distributed under the terms and conditions of the Creative Commons Attribution license (http://creativecommons.org/licenses/by/4.0/). 